\title{
Spirometra (Pseudophyllidea, Diphyllobothriidae) Severely Infecting Wild-Caught Snakes from Food Markets in Guangzhou and Shenzhen, Guangdong, China: Implications for Public Health
}

\author{
Fumin Wang, ${ }^{1}$ Weiye $\mathrm{Li}^{2}{ }^{2}$ Liushuai Hua, ${ }^{2}$ Shiping Gong, ${ }^{2}$ Jiajie Xiao, ${ }^{1}$ Fanghui Hou, ${ }^{1}$ \\ Yan $\mathrm{Ge}^{2}$ and Guangda Yang ${ }^{1}$ \\ ${ }^{1}$ Guangdong Provincial Wildlife Rescue Center, Guangzhou 510520, China \\ ${ }^{2}$ Guangdong Entomological Institute (South China Institute of Endangered Animals), No. 105, Xin Gang Road West, \\ Guangzhou 510260, China
}

Correspondence should be addressed to Shiping Gong; gsp621@163.com

Received 29 August 2013; Accepted 21 October 2013; Published 16 January 2014

Academic Editors: S. A. Babayan, M. Chaudhuri, and E. L. Jarroll

Copyright (C) 2014 Fumin Wang et al. This is an open access article distributed under the Creative Commons Attribution License, which permits unrestricted use, distribution, and reproduction in any medium, provided the original work is properly cited.

\begin{abstract}
Sparganosis is a zoonotic disease caused by the spargana of Spirometra, and snake is one of the important intermediate hosts of spargana. In some areas of China, snake is regarded as popular delicious food, and such a food habit potentially increases the prevalence of human sparganosis. To understand the prevalence of Spirometra in snakes in food markets, we conducted a study in two representative cities (Guangzhou and Shenzhen), during January-August 2013. A total of 456 snakes of 13 species were examined and 251 individuals of 10 species were infected by Spirometra, accounting for $55.0 \%$ of the total samples. The worm burden per infected snake ranged from 1 to 213 , and the prevalence in the 13 species was $0 \sim 96.2 \%$. More than half (58.1\%) of the spargana were located in muscular tissue, $25.6 \%$ in subcutaneous tissue, and $16.3 \%$ in coelomic cavity. The results indicated that Spirometra severely infected snakes in food markets in Guangzhou and Shenzhen, implying that eating snakes has great health risk and improper cooking methods may increase the risk of Spirometra infection in humans in China. Additional steps should be considered by the governments and public health agencies to prevent the risk of snake-associated Spirometra infections in humans.
\end{abstract}

\section{Introduction}

Spargana of Spirometra can parasitize in human body and result in sparganosis, which is an important foodborne parasitic zoonosis [1]. There are three hosts through the life cycle of Spirometra, including two intermediary hosts and a definitive host. The first intermediate host is the small crustaceans (Cyclops genus); then tadpoles, frogs, fish, and snakes could be infected by Spirometra and become the second intermediate hosts; finally, carnivores such as birds, dogs, and cats serve as the definitive hosts of Spirometra [2]. Humans are accidental hosts taking the place of either the second intermediary host or of the definitive host, notably by consuming raw meat [3].

Sparganosis has been reported in 39 countries in the world, and it mainly occurs in east and southeast Asia and has also been reported in Europe, America, Africa, and Australia [4]. In China, human sparganosis has been reported in 25 provinces [5]. The first case of human sparganosis was reported in 1882 in Xiamen of Fujian Province, China [6]. To date, over 1000 cases of human sparganosis have been reported in mainland China, of which, $10 \%$ of the cases occurred in Guangdong Province [7].

The high prevalence of sparganosis in Guangdong Province may be related to the local dietary habit, where snake is regarded as popular delicious and nutritious food $[8,9]$. In Guangzhou, about half of the local restaurants provide wild-caught snakes, and the annual trade volume ever reached 3,612 tons $[8,10]$. To make matters worse, many people enjoy eating halfcooked or even completely raw meat/ skin/gall bladder of snakes, without considering the high risk of infection by parasites. 
TABLE 1: Essential information of the 456 snake samples from food markets in Guangzhou and Shenzhen, China.

\begin{tabular}{|c|c|c|c|c|c|c|}
\hline Species of snakes & $\begin{array}{c}\text { Source of } \\
\text { samples }\end{array}$ & $\begin{array}{c}\text { Number of } \\
\text { samples }\end{array}$ & $\begin{array}{c}\text { Range of body } \\
\text { length }(\mathrm{cm})\end{array}$ & $\begin{array}{c}\text { Medians of body } \\
\text { length }(\mathrm{cm})\end{array}$ & $\begin{array}{c}\text { Range of body } \\
\text { weight }(\mathrm{g})\end{array}$ & $\begin{array}{c}\text { Medians of } \\
\text { body weight }(\mathrm{g}) \\
\end{array}$ \\
\hline \multicolumn{7}{|l|}{ Viperidae } \\
\hline Deinagkistrodon acutus & Guangzhou & 5 & $105 \sim 123$ & 110 & $665.0 \sim 1,155.7$ & 723.8 \\
\hline \multicolumn{7}{|l|}{ Elapidae } \\
\hline Bungarus multicinctus & $\begin{array}{c}\text { Guangzhou and } \\
\text { Shenzhen }\end{array}$ & 13 & $75 \sim 120$ & 100 & $66.0 \sim 295.1$ & 178.2 \\
\hline Naja atra & Guangzhou & 28 & $88 \sim 173$ & 118.5 & $167.0 \sim 1,925.8$ & 663.95 \\
\hline \multicolumn{7}{|l|}{ Colubridae } \\
\hline Dinodon rufozonatum & Shenzhen & 44 & $81 \sim 125$ & 98.5 & $104.5 \sim 334.4$ & 162.9 \\
\hline Elaphe carinata & Guangzhou & 11 & $146 \sim 211$ & 178 & $831.4 \sim 2,167.0$ & $1,121.6$ \\
\hline E. taeniura & Guangzhou & 26 & $83 \sim 163$ & 123 & $63.7 \sim 334.0$ & 178.35 \\
\hline Enhydris bocourti & Guangzhou & 9 & $70 \sim 85$ & 80 & $337.5 \sim 487.0$ & 406.3 \\
\hline En. chinensis & Guangzhou & 29 & $27 \sim 72$ & 46 & $15.3 \sim 230.3$ & 53.2 \\
\hline En. plumbea & Guangzhou & 28 & $30 \sim 47$ & 39 & $15.1 \sim 63.8$ & 27.75 \\
\hline Ptyas korros & $\begin{array}{c}\text { Guangzhou and } \\
\text { Shenzhen }\end{array}$ & 55 & $91 \sim 162$ & 121 & $109.0 \sim 514.0$ & 222.3 \\
\hline P. mucosus & $\begin{array}{l}\text { Guangzhou and } \\
\text { Shenzhen }\end{array}$ & 49 & $150 \sim 240$ & 202 & $433.3 \sim 2,346.0$ & 948 \\
\hline Xenochrophis piscator & $\begin{array}{c}\text { Guangzhou and } \\
\text { Shenzhen }\end{array}$ & 107 & $53 \sim 110$ & 82 & $26.6 \sim 419.9$ & 191.7 \\
\hline Zoacys dhumnades & $\begin{array}{l}\text { Guangzhou and } \\
\text { Shenzhen }\end{array}$ & 52 & $96 \sim 220$ & 172 & $517.0 \sim 1,165.4$ & 606.6 \\
\hline
\end{tabular}

Based on the high prevalence of sparganosis and the unhealthy habit of eating snakes in Guangdong, we conducted this survey to further understand the prevalence of Spirometra infection in common snakes in food markets. The purpose of this study was to assess the risks of human spargana infection caused by the consumption of wild-caught snakes and provide scientific foundation for preventing the human sparganosis.

\section{Materials and Methods}

2.1. Snake Samples. The survey was conducted between January and August of 2013. A total of 456 snake samples (252 living and 204 frozen snakes) were selected from the seized snakes from food markets in Guangzhou and Shenzhen, South China. The snake samples were kept in the Guangdong Provincial Wildlife Rescue Center by local wildlife management department. With the permission from local wildlife management department, we conducted this work. The living snake samples were euthanized using ethyl ether anesthesia before checking spargana. Snake species were identified according to their morphological characteristics [11].

2.2. Parasite Inspection. The specimens were dissected to examine the infection by Spirometra according to the methods of Wang et al. [12]. Their body length and weight were measured before dissection. For each individual, the skin was entirely peeled off from neck to the tip of tail and the visceral mass from the esophagus and trachea to the cloaca was isolated from the body. Then, the number of Spirometra located in muscle tissue, subcutaneous tissue, and coelom (including viscera) was respectively counted in order to investigate the distribution of Spirometra inside the snake body. The data was processed with Excel 2007 Software and SPSS. The nonparametric Kruskal-Wallis test was used to compare the difference of the number of worms among the muscle tissue, subcutaneous tissue, and coelom of snakes.

\section{Results}

These selected snake samples composed 13 species, including Deinagkistrodon acutus, Bungarus multicinctus, Naja atra, Dinodon rufozonatum, Elaphe carinata, E. taeniura, Enhydris bocourti, En. chinensis, En. plumbea, Ptyas korros, P. mucosus, Xenochrophis piscator, and Zoacys dhumnades. The body length of the 456 snake samples ranged from 27 to $240 \mathrm{~cm}$ and the body weight ranged from 15.1 to 2,346.0 g. Essential information including sample source, number of samples of each species, body length and weight of each snake was shown in Table 1.

Overall, 5,698 worms of Spirometra were isolated from 251 snakes, accounting for $55.0 \%$ of the total examined snake samples. The exterior view of Spirometra was shown in Figure 1. The worm burden per infected snake ranged from 1 to 213 , while the prevalence in the 13 examined species was $0 \sim 96.2 \%$ and the mean infection intensity was 12.5 (Table 2). More than half (58.1\%) of the spargana located in muscular tissue, $25.6 \%$ in subcutaneous tissue, and $16.3 \%$ in the coelomic cavity (Figures 2 and 3 ). The nonparametric test 
TABLE 2: Prevalence, intensity, and parasitizing locations of Spirometra found in 13 species of wild-caught snakes from food markets in Guangzhou and Shenzhen, China.

\begin{tabular}{|c|c|c|c|c|c|c|}
\hline \multirow{2}{*}{ Species of snakes } & \multicolumn{3}{|c|}{ Infection of Spirometra } & \multicolumn{3}{|c|}{ Locations of Spirometra } \\
\hline & Prevalence (\%) & Intensity of infection & Mean intensity of infection & Muscle & Subcutaneous tissue & Coelom \\
\hline \multicolumn{7}{|l|}{ Viperidae } \\
\hline Deinagkistrodon acutus & 60.0 & $0 \sim 34$ & 9.6 & 32 & 14 & 2 \\
\hline \multicolumn{7}{|l|}{ Elapidae } \\
\hline Bungarusmulticinctus & 7.7 & $0 \sim 5$ & 0.4 & 0 & 0 & 5 \\
\hline Naja atra & 14.3 & $0 \sim 3$ & 0.3 & 6 & 1 & 1 \\
\hline \multicolumn{7}{|l|}{ Colubridae } \\
\hline Dinodon rufozonatum & 79.5 & $0 \sim 65$ & 14.4 & 407 & 137 & 89 \\
\hline Elaphe carinata & 63.6 & $0 \sim 172$ & 42.3 & 232 & 180 & 53 \\
\hline E. taeniura & 15.4 & $0 \sim 5$ & 0.6 & 12 & 0 & 4 \\
\hline Enhydris bocourti & 0 & 0 & 0 & 0 & 0 & 0 \\
\hline En. chinensis & 0 & 0 & 0 & 0 & 0 & 0 \\
\hline En.plumbea & 0 & 0 & 0 & 0 & 0 & 0 \\
\hline Ptyas korros & 40.0 & $0 \sim 65$ & 3.3 & 72 & 68 & 43 \\
\hline P. mucosus & 81.6 & $0 \sim 81$ & 12.0 & 341 & 161 & 88 \\
\hline Xenochrophis piscator & 79.4 & $0 \sim 133$ & 15.1 & 1,138 & 259 & 216 \\
\hline Zoacys dhumnades & 96.2 & $0 \sim 213$ & 41.1 & 1,072 & 636 & 429 \\
\hline Total & - & $0 \sim 213$ & - & 3,312 & 1,456 & 930 \\
\hline Means & 55.0 & - & 12.5 & 7 & 3 & 2 \\
\hline
\end{tabular}

Note: Kruskal-Wallis test showed significant difference among the number of worms in muscle, subcutaneous tissue, and coelom $(P<0.05)$.

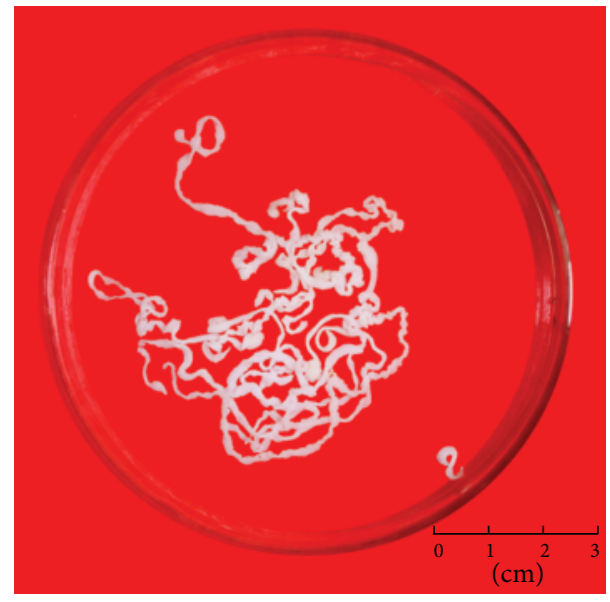

FIGURE 1: The exterior view of Spirometra isolated from snakes.

showed that the density distribution among the muscle tissue, subcutaneous tissue, and coelom was significantly different $(P<0.05)$ (Table 2, Figure 3).

The prevalence and infection intensity of Spirometra had large differences among snake species (Figure 3). Snake species in Elapidae had lower prevalence and infection intensity of Spirometra. In Enhydris, 3 species, En. bocourti, En. chinensis, and En. Plumbea, were even free of Spirometra infection. Spirometra infection was common prevalence in the snake species, including Z. dhumnades, Di. rufozonatum, $X$. piscator, E. carinata, P. korros, D. acutus, and P. mucosus.

\section{Discussion}

Colubridae and Elapidae are the main target species in food markets in China $[10,13]$. In this investigation, we checked 13 common snake species belonging to 3 families ( 1 species in Viperidae, 2 species in Elapidae, and 10 species in Colubridae). The results indicate that Spirometra severely infected wild-caught snakes in food markets in Guangzhou and Shenzhen. More than half $(55.0 \%)$ of the snakes were infected by Spirometra and the mean intensity of infection reached 12.5 worms per snake. Similar results were obtained in the studies of other areas or other species of snakes [12]. Due to the high prevalence of infection in snakes, consuming snakes has great risk of infection by sparganosis.

In this survey, the prevalence and intensity of Spirometra infection were different among snake species. There seems to be relevance between Spirometra infection and the feeding habits of snakes. Generally, nonpoisonous snakes prefer to prey frogs [11] and these species seem more susceptible to Spirometra infection. There is an interesting phenomenon that three species of genus Enhydris which dwells in the water and mainly prey on fishes and tadpoles were free of infection by Spirometra. In theory, those snakes have more opportunities to contact Cyclops, the first intermediate host of Spirometra, and are prone to be infected by Spirometra through eating the second intermediate hosts (tadpoles and frogs). As a result, we infer these snakes may have some resistance to Spirometra and this is worth conducting further study. To further understand the reasons of Spirometra infection in snake, more detailed survey on the habitats and dietary habit of these snakes are necessary. However, it is a regret that we cannot trace the source of these snakes. As 


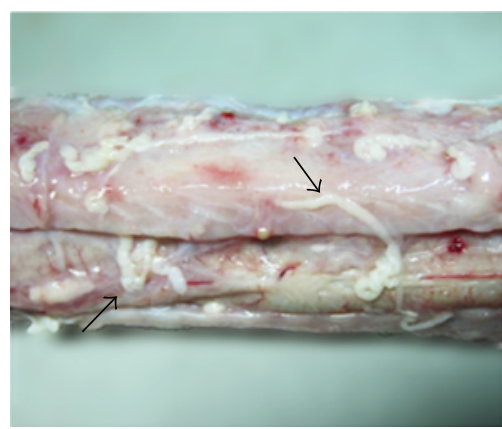

(a)

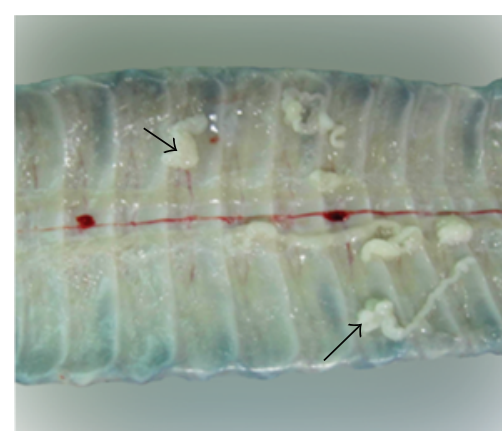

(b)

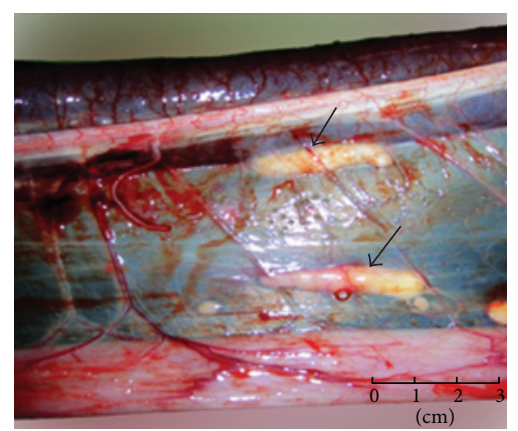

(c)

Figure 2: Spirometra located in muscle tissue (a), subcutaneous issue (b), and coelom (c) of Zoacys dhumnades. Arrows point to Spirometra.

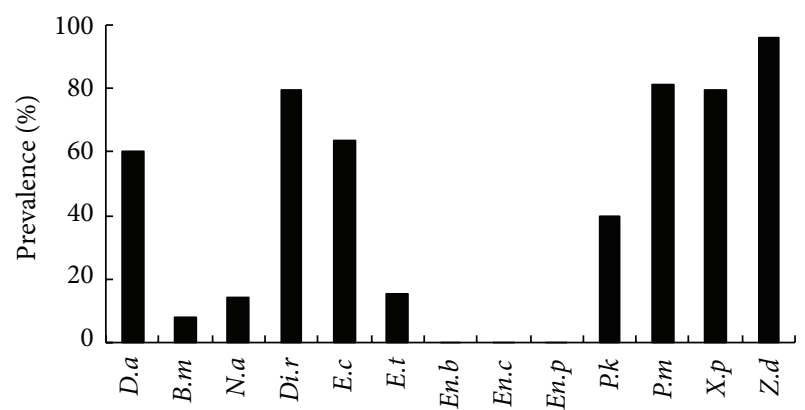

(a)

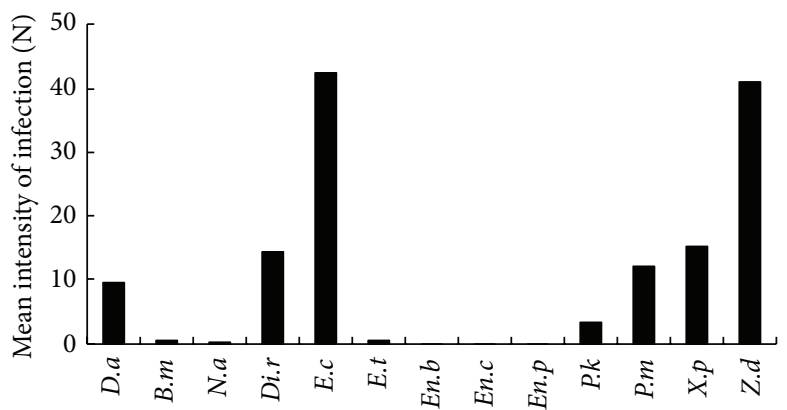

(b)
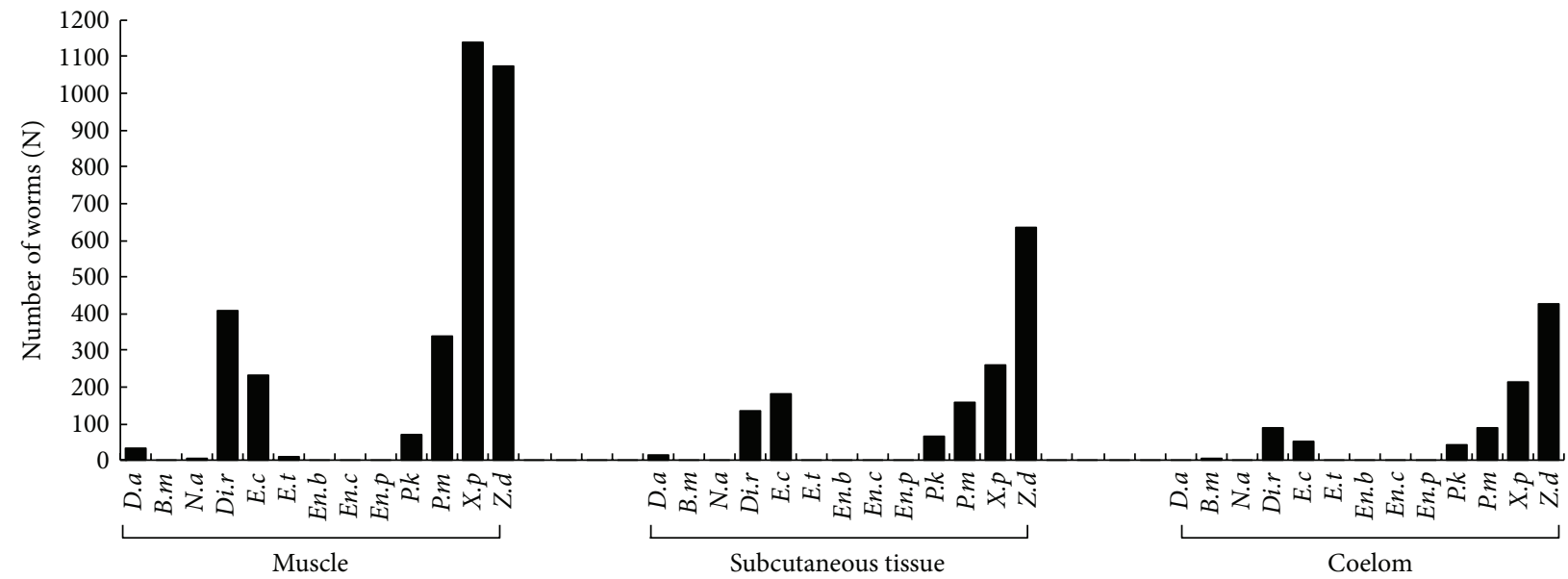

(c)

FIgURE 3: Prevalence (a), intensity (b), and parasitizing locations (c) of Spirometra found in 13 species of wild-caught snakes. Letters on the horizontal axis for each column are the abbreviation of snake Latin names: D.a-Deinagkistrodon acutus, B.m-Bungarus multicinctus, N.a-Naja atra, Di.r-Dinodon rufozonatum, E.c-Elaphe carinata, E.t-Elaphe taeniura, En.b-Enhydris bocourti, En.c-Enhydris chinensis, En.p-Enhydris plumbea, P.k-Ptyas korros, P.m-Ptyas mucosus, X.p-Xenochrophis piscator, and Z.d-Zoacys dhumnades.

the centers of snake consumption, snakes in food markets of Guangzhou and Shenzhen may come from not only local but also other provinces, even other countries $[14,15]$.

In China, there are a lot of cases of human sparganosis caused by eating raw meat of snakes and frogs, drinking snake blood, and swallowing snake gall bladder [16]. Improper cooking methods of snakes will also increase the risk of infection, such as snake skin salad and halfcooked snake meat. In addition, Spirometra may contaminate tableware and food in the process of cooking snake meat. In the year of 2011, a patient suffered from bronchial sparganosis because he had a history of ingesting raw frogs, snakes, and drinking raw snake blood [17]. Another case of cerebral sparganosis reported in 2012 was caused by eating frogs and snakes [18]. In a separate report in 2003, all of the 11 patients infected by Spirometra had the habit of eating raw meat and skin of 
animals and 6 of them ate snake meat, blood, or snake gall [19]. In 104 cases from 2000 to 2006, 53.9\% were caused by eating snakes or frogs [16].

Our study indicated that eating wild-caught snakes has great health risk and improper cooking methods may increase the risk of Spirometra infection. In recent years, eating snakes and other wild-caught animals have resulted in numerous cases of human sparganosis [16]. However, the traditional habit of eating snakes still prevails in southern China, especially in Guangdong Province [8]. Based on this study, we present three suggestions for preventing human sparganosis: (1) the harm and epidemiology of sparganosis should be publicized and popularized, (2) the illegal trade in wild-caught snakes should be effectively controlled and the quarantine of snakes in food markets should be strengthen, and (3) long-term monitoring of the sparganosis of snakes in food markets should be conducted to provide scientific basis for preventing and controlling the sparganosis.

\section{Conflict of Interests}

The work is all original research carried out by the authors. All authors agree with the contents of the paper and its publication. No part of the research has been published in any form elsewhere. All sources of funding are acknowledged in the paper, and authors declared no potential conflict of interests that could influence the publication of the work.

\section{Authors' Contribution}

Fumin Wang and Weiye Li contributed equally to this work.

\section{Acknowledgments}

The authors would like to thank Ms. Guoling Chen, Mr. Yufeng Wei, Ms. Xiaonan Li, and Mr. Youhong Peng for their help during the investigation and paper preparation. This work was supported financially by the Forestry Science \& Technology Innovation Program of Guangdong Province, China (no. 2012KJCX017-01) and the Scientific and Technological Plan Project of Guangdong Province (no. 2010B031000012).

\section{References}

[1] P. Zhou, N. Chen, R.-L. Zhang, R.-Q. Lin, and X.-Q. Zhu, "Foodborne parasitic zoonoses in China: perspective for control," Trends in Parasitology, vol. 24, no. 4, pp. 190-196, 2008.

[2] G. R. Yin, Y. B. Yang, and P. Z. Li, "Common food-borne parasitic diseases and their prevention and control in China," Chinese Journal of Disease Control \& Prevention, vol. 10, pp. 400-402, 2006.

[3] S. Magnino, P. Colin, E. Dei-Cas et al., "Biological risks associated with consumption of reptile products," International Journal of Food Microbiology, vol. 134, no. 3, pp. 163-175, 2009.

[4] G. L. Wu, Human Parasitology, People's Medical Publishing House, Beijing, China, 3rd edition, 2005.
[5] M.-W. Li, H.-Q. Song, C. Li et al., "Sparganosis in mainland China," International Journal of Infectious Diseases, vol. 15, no. 3, pp. e154-e156, 2011.

[6] X. M. Zhan, Human Parasitology, People's Medical Publishing House, Beijing, China, 1st edition, 2005.

[7] M.-H. Qiu and M.-D. Qiu, "Human plerocercoidosis and sparganosis: II. A historical review on pathology, clinics, epidemiology and control," Chinese Journal of Parasitology and Parasitic Diseases, vol. 27, no. 3, pp. 251-260, 2009.

[8] L. Xu, M. Meng, and F. Yin, "Information on the trade in wild animals and plants in China 2007," TRAFFIC East Asia, p. 12, 2007.

[9] M. Meng, L. L. Lu, F. Yin et al., "Status of wildlife trade as food in south China," Chinese Journal of Wildlife, vol. 3, pp. 158-160, 2009.

[10] D. Z. Liu, H. Tian, and Z. M. Song, "Report on a trade survey of the snakes in some Chinese key cities," in Proceedings of the Snake Resource Protecting Seminar, pp. 12-33, Beijing, China, 2007.

[11] E. M. Zhao, Snakes of China, Anhui Science and Technology Press, Hefei, China, 2006.

[12] F. Wang, L. Zhou, S. Gong et al., "Severe infection of wild-caught snakes with spirometra erinaceieuropaei from food markets in Guangzhou, China involves a risk for zoonotic sparganosis," Journal of Parasitology, vol. 97, no. 1, pp. 170-171, 2011.

[13] S. P. Gong, H. J. Hu, H. T. Shi et al., "Surveys of amphibia and reptilia in the Qiaoxi market, Huizhou, Guangdong province, China," Proceedings of the Zoological Society of Guangdong Province, China, p. 90, 2007.

[14] Y. Li and D. Li, "The dynamics of trade in live wildlife across the Guangxi border between China and Vietnam during 1993-1996 and its control strategies," Biodiversity and Conservation, vol. 7, no. 7, pp. 895-914, 1998.

[15] H. Y. He and X. B. Peng, "A preliminary survey of snake-markets in Guangzhou," Sichuan Journal of Zoology, vol. 3, pp. 139-142, 1999.

[16] Z. J. Wu, Y. Chen, X. L. Qiu et al., "An investigation of plerocercoid infection of frogs in Guiyang city and an analysis on clinical characteristics of 104 cases," Journal of Guiyang Medical College, vol. 32, pp. 140-141, 2007.

[17] X. H. Chen, A case report of bronchial Sparganosis mansoni and literature review [M.S. thesis], Guangxi Medical University, Guangxi, China, 2012.

[18] X. Z. Zhu, A. Ma, and Y. Wang, "Report of a case of cerebral sparganosis," Modern Practical Medicine, vol. 24, p. 1313, 2012.

[19] B. L. Lin, L. B. Chen, X. H. Zhang et al., "Eleven cases of sparganosis analysis in Guangdong," Journal of Sun Yat-Sen University, vol. 24, pp. 79-80, 2003. 

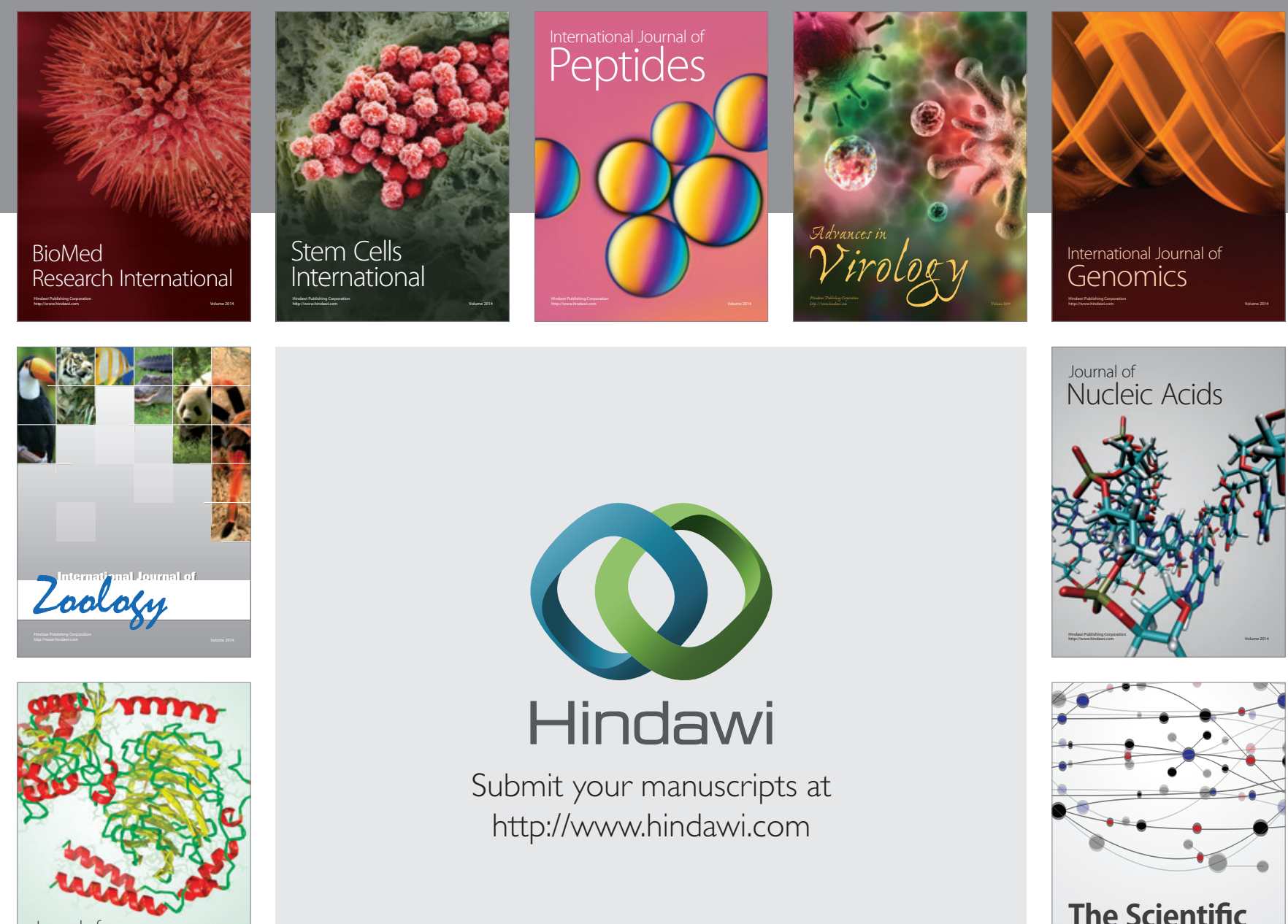

Submit your manuscripts at

http://www.hindawi.com

Journal of
Signal Transduction
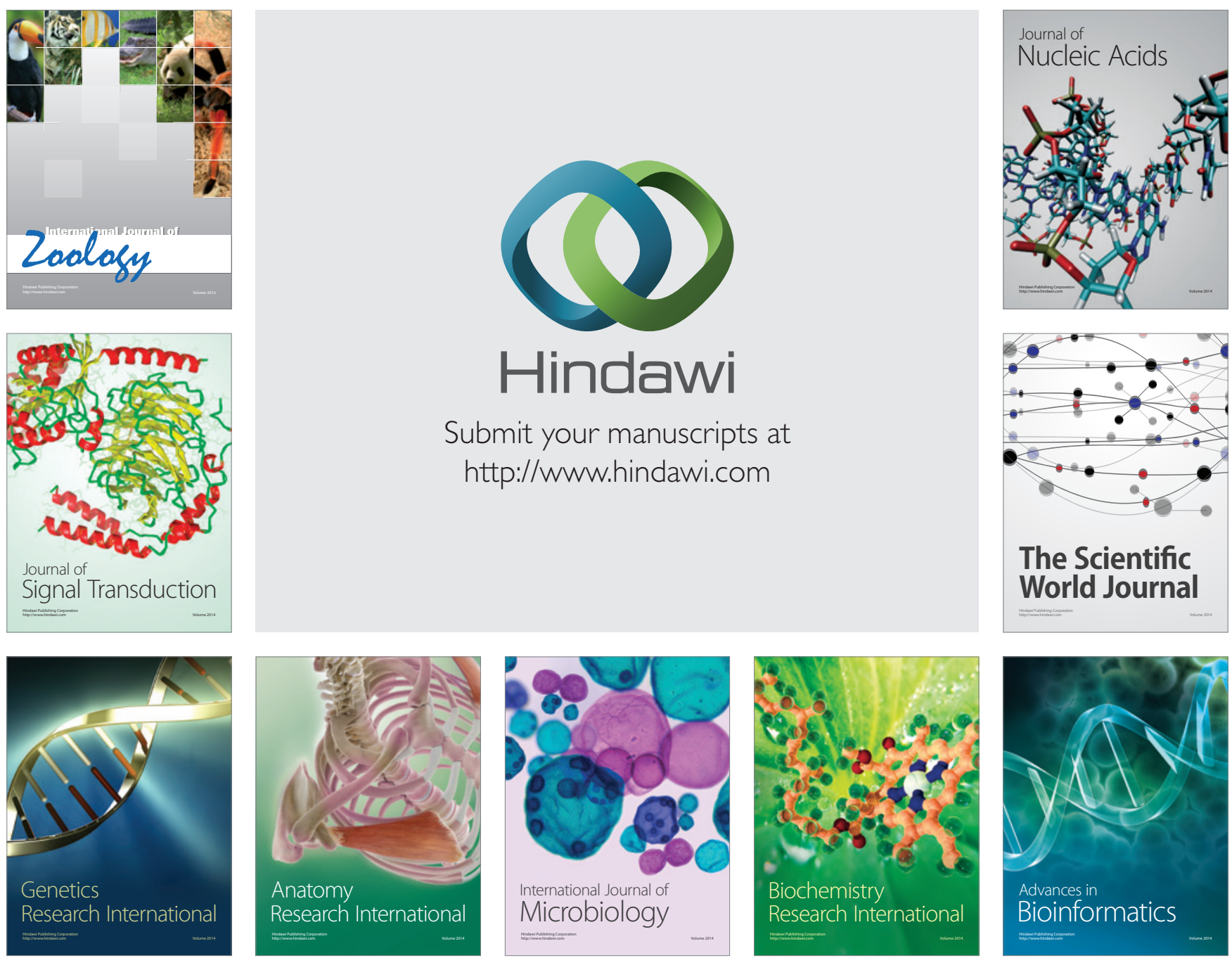

The Scientific World Journal
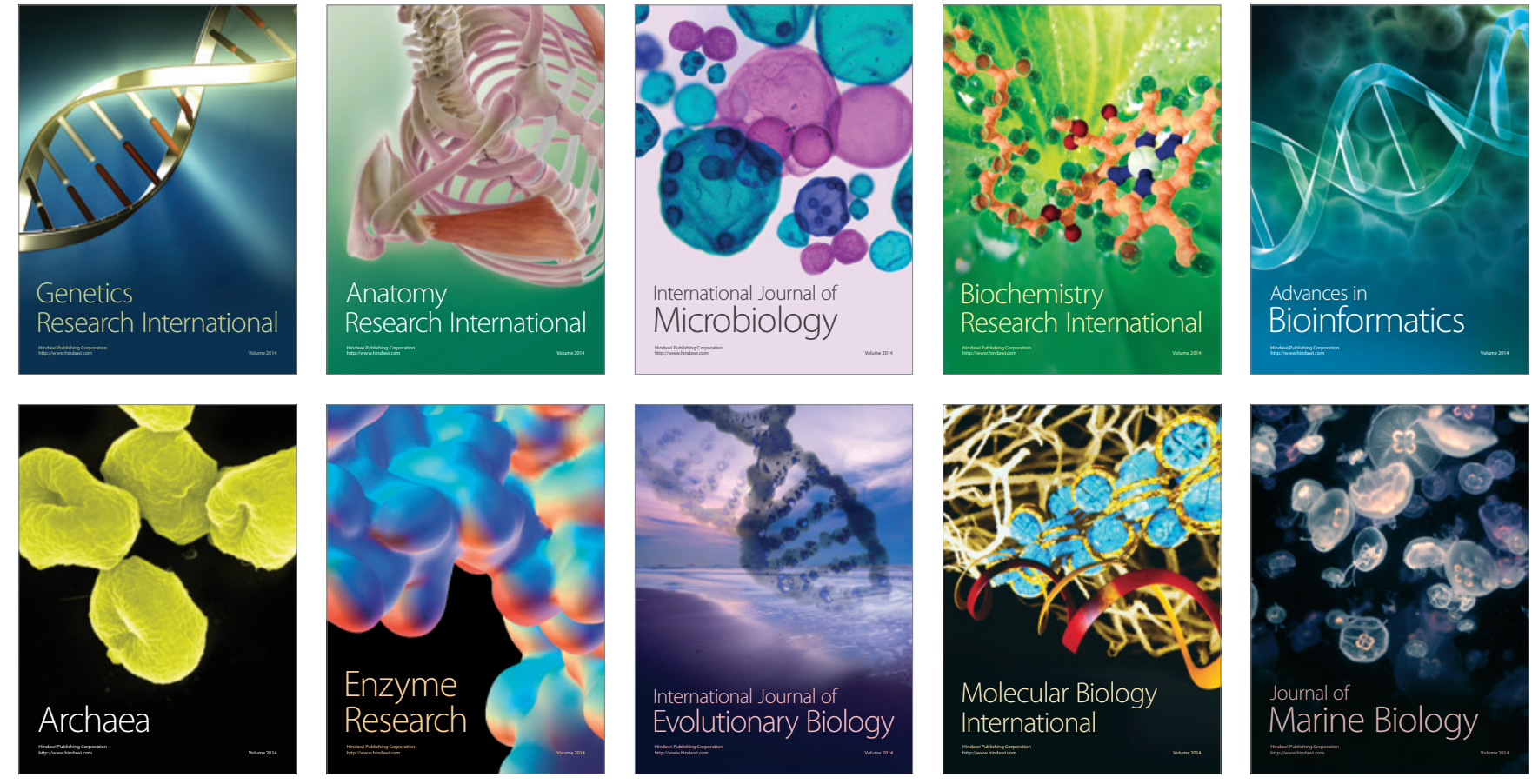